\title{
BMJ Open Does ethnic diversity explain intra-UK variation in mortality? A longitudinal cohort study
}

\author{
Lauren Schofield, ${ }^{1}$ David Walsh, ${ }^{2}$ Zhiqiang Feng, ${ }^{3}$ Duncan Buchanan, ${ }^{4}$ \\ Chris Dibben, ${ }^{3}$ Colin Fischbacher, ${ }^{1}$ Gerry McCartney, ${ }^{5}$ Rosalia Munoz-Arroyo, ${ }^{1}$ \\ Bruce Whyte ${ }^{2}$
}

\section{To cite: Schofield L, Walsh D, Feng Z, et al. Does ethnic diversity explain intra-UK variation in mortality? A longitudinal cohort study. BMJ Open 2019;9:e024563. doi:10.1136/ bmjopen-2018-024563 \\ - Prepublication history and additional material for this paper are available online. To view these files, please visit the journal online (http://dx.doi. org/10.1136/bmjopen-2018- 024563).}

Received 7 June 2018 Revised 5 December 2018 Accepted 11 February 2019

Check for updates

(c) Author(s) (or their employer(s)) 2019. Re-use permitted under CC BY-NC. No commercial re-use. See rights and permissions. Published by BMJ.

${ }^{1}$ Information Services Division, Edinburgh, UK

${ }^{2}$ Glasgow Centre for Population Health, Glasgow, UK

${ }^{3}$ University of Edinburgh,

Edinburgh, UK

${ }^{4}$ ISD Scotland, Edinburgh, UK ${ }^{5} \mathrm{NHS}$ Health Scotland, Glasgow, UK

Correspondence to

Dr David Walsh;

david.walsh.2@glasgow.ac.uk

\section{ABSTRACT}

Objectives It has been proposed that part of the explanation for higher mortality in Scotland compared with England and Wales, and Glasgow compared with other UK cities, relates to greater ethnic diversity in England and Wales. We sought to assess the extent to which this excess was attenuated by adjusting for ethnicity. We additionally explored the role of country of birth in any observed differences.

Setting Scotland and England and Wales; Glasgow and Manchester.

Participants We used the Scottish Longitudinal Study and the Office for National Statistics Longitudinal Study of England and Wales (2001-2010). Participants (362 491 in total) were aged 35-74 years at baseline.

Primary outcome measures Risk of all-cause mortality between 35 and 74 years old in Scotland and England and Wales, and in Glasgow and Manchester, adjusting for age, gender, socioeconomic position (SEP), ethnicity and country of birth.

Results $18 \%$ of the Manchester sample was non-White compared with 3\% in Glasgow (England and Wales: 10.4\%; Scotland: $1.2 \%)$. The mortality incidence rate ratio was $1.33(95 \% \mathrm{Cl} 1.13$ to 1.56$)$ in Glasgow compared with Manchester. This reduced to 1.25 (1.07 to 1.47) adjusting for SEP, and to 1.20 (1.02 to 1.42) adjusting for ethnicity and country of birth. For Scotland versus England and Wales, the corresponding figures were $18 \%$ higher mortality, reducing to $10 \%$, and then $7 \%$. Non-Whites born outside the UK had lower mortality. In the Scottish samples only, non-Whites born in the UK had significantly higher mortality than Whites born in the UK.

Conclusions The research supports the hypothesis that ethnic diversity and migration from outside UK play a role in explaining Scottish excess mortality. In Glasgow especially, however, a large excess remains: thus, previously articulated policy implications (addressing poverty, vulnerability and inequality) still apply.

\section{INTRODUCTION}

High levels of 'excess mortality' (defined as higher mortality after adjustment for differences in socioeconomic circumstances) have been observed in Scotland compared with England and Wales, and particularly in

\section{Strengths and limitations of this study}

- The relationships among ethnicity, country of birth and mortality are explored between different countries of the UK.

- The impact of differences in the ethnic composition of the populations on excess mortality is quantified.

- Analyses employ longitudinal data taken from national censuses.

- Analyses are based on a large sample size of over 350000 individuals

- Limitations include the use of a binary White/nonWhite ethnicity variable, and the outcome being limited to all-cause mortality.

Scotland's largest city, Glasgow, in comparison to other, similarly deprived, postindustrial cities in the UK such as Liverpool, Manchester and Belfast. ${ }^{1-6}$ Recently published research identified the most likely underlying causes of this excess, with the findings endorsed by leading figures in public health and other relevant disciplines. ${ }^{78}$ In large part, the excess was deemed attributable to a heightened vulnerability among the population, created by a toxic combination of adverse historical living conditions allied to detrimental political decision-making at different levels of government. Alongside these principal contributory factors, however, the evidence also suggested that a broad range of other, smaller, factors played a part. These included characteristics of some of the comparator populations, which placed Scotland and Glasgow at a further relative disadvantage. One such proposed characteristic was greater levels of ethnic diversity in England and Wales and, in particular, Manchester, given that this has been associated with lower than expected mortality among some (in particular, deprived) UK populations. ${ }^{9}$

However, the links between ethnicity and health are extremely 
complex. ${ }^{10} 11$ Furthermore, there are important differences in the health-related profiles of non-White minority groups in Scotland compared with England. In most developed countries, ethnic inequalities in health are to a large extent an extension of socioeconomic inequalities, given the more disadvantaged socioeconomic profile of most ethnic minority groups. ${ }^{12}{ }^{13}$ However, in Scotland, the socioeconomic profile of many non-White minority groups is much less disadvantaged, and quite different to that in England. ${ }^{14}$ The complexity also extends to understanding other important underlying reasons for differences in health status between ethnic groups. Included in this is evidence of a 'healthy migrant effect', that is the better health outcomes associated with those who have the resources to migrate. ${ }^{101516}$ This is particularly important as mortality rates have been shown to differ between non-White ethnic groups born outside the UK and those born in the UK. ${ }^{17}{ }^{18}$

The principal aim of this study was to assess the extent to which the high levels of excess mortality observed in Glasgow and Scotland were attenuated by adjusting for levels of ethnic diversity. However, given the above, a secondary aim was to explore the additional effect of country of birth, reflecting differences in health status of migrants born outside the UK and their offspring.

\section{METHODS}

The Scottish Longitudinal Study ${ }^{19}$ (a $5.3 \%$ sample of the Scotland Census linked to life events data including death registrations) and the Office for National Statistics Longitudinal Study of England and Wales ${ }^{20}$ (a $1 \%$ sample of the England and Wales Census, also linked to life events data including individual mortality records) were employed. Analyses of these 'restricted access' data sets were enabled by the use of E-DataSHIELD methodology, which has been described previously. ${ }^{61}$

The analyses compared all-cause mortality rates in Glasgow with Manchester (both cities defined by local authority boundaries, as used previously ${ }^{46}$ ), and in Scotland with England and Wales, using Poisson regression models, adjusting for age, sex, various measures of socioeconomic position (SEP), ethnicity and country of birth (all defined below). Manchester has been previously identified as the most appropriate comparator city for the analyses, given its much greater levels of ethnic diversity compared with Glasgow. $^{7}$ (UK analyses have shown high levels of excess mortality to be observed in Glasgow in comparison to Liverpool, Belfast and Manchester. However, compared with Glasgow, ethnic diversity (in terms of the relative size of the non-White population) has been shown to be very similar in Liverpool and lower in Belfast). As samples of national census data, both data sources are designed to be representative of their respective national populations ${ }^{1920}$; comparisons with published 2001 census data confirmed that the city samples were also broadly representative in terms of age, sex, socioeconomic measures (eg, housing tenure, car access) and ethnicity.
Person years were used as the offset in the models and final fitted models were checked for issues of overdispersion. Individuals were followed from 2001 to the end of 2010 , with person years calculated from a start date of 29 April 2001 (the date of the census) to the end date of the follow-up period (31 December 2010), or to a date of death prior to 31 December 2010, or to a first 'embarkation' date (emigration). Cohort members who emigrated and then returned were excluded. The main analyses focused on those aged 35-74 years, an age group for which particularly high levels of excess mortality have been observed in Scotland. ${ }^{78}$ However, analyses for all ages, and 0-64 years, were additionally undertaken. Age was defined as at April 2001 (census date).

Ethnicity was defined based on how individuals identified themselves in response to questions contained in the Scotland, and England and Wales, Censuses. A binary variable (White vs non-White) was derived because of the small number of deaths within each of the more detailed ethnicity categories. Country of birth was categorised as those born in the UK and Ireland and those born elsewhere to match previous analyses among a Scotland census-based cohort. ${ }^{18}$

Replicating previous analyses of Scottish excess mortality based on the same data sets, ${ }^{6}$ housing tenure, access to a car/van, economic activity and educational attainment were employed as the principal measures of SEP (note that household income is not included in the Scottish and English/Welsh censuses). In addition, deciles of the Carstairs and Morris area deprivation index for 2001 (derived from England and Wales census wards and Scottish postcode sectors, and described elsewhere ${ }^{3}$ ) were used; however, due to issues of colinearity, and assessments of the best-fitting SEP variables in the models, these were ultimately only included in the all ages and 0-64 years models (and not for any cities-based analyses). The latter models (0-64 years) also excluded the economic activity and educational attainment variables, as they were only available for those aged 16-74 years.

A full list of all independent variables and categories used in the models (35-74 years) is shown in table 1 . Similar information for the other samples (all ages and 0-64 years) is included in the online appendix tables A and $\mathrm{B}$. Additional background information (total person years, numbers of deaths and age-standardised mortality rates by geographical location) is included in online appendix table $\mathrm{C}$ ).

The E-DataSHIELD is written in R; data management and descriptive analyses were performed using Stata.

\section{Patient and public involvement}

Patients were not involved in this study.

\section{RESULTS}

Table 1 shows that in 2001, 10.4\% of the English and Welsh 35-74years old sample was classed as non-White, approximately two-thirds of whom had been born outside 


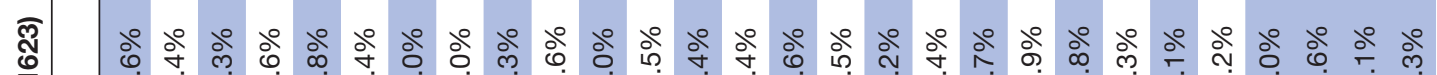
II

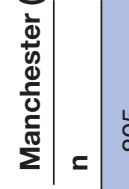

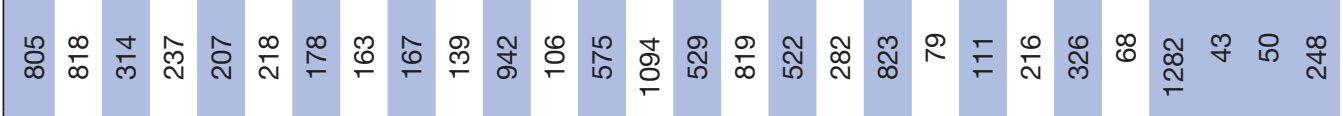

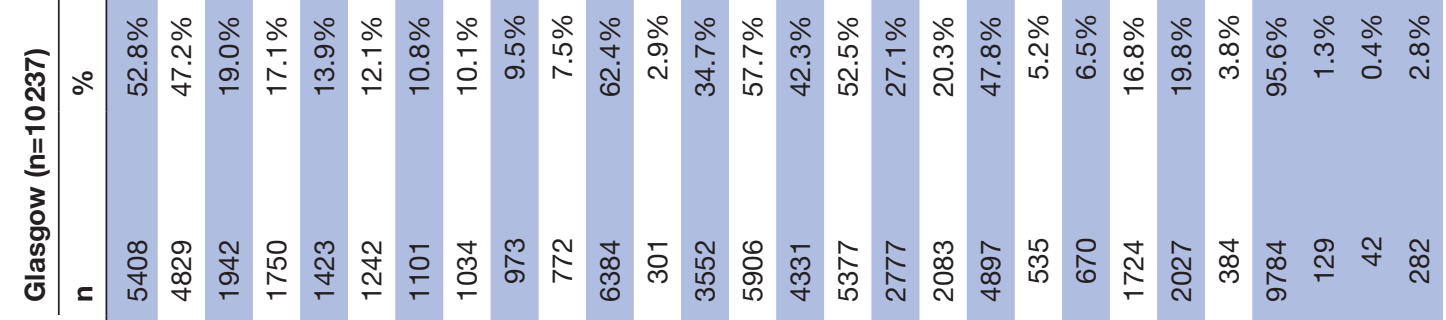

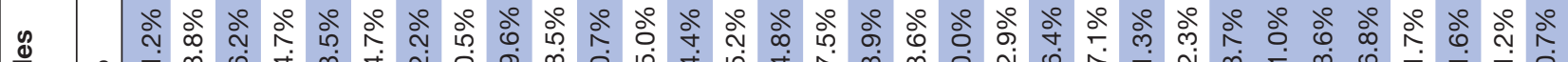

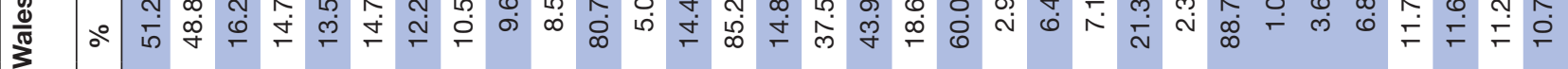
일

के

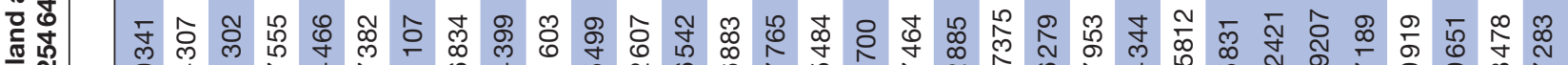

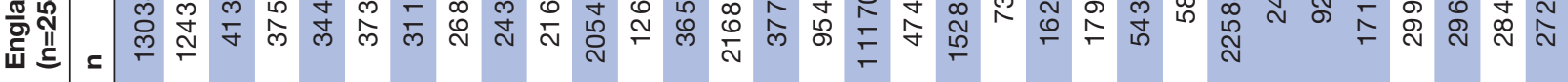

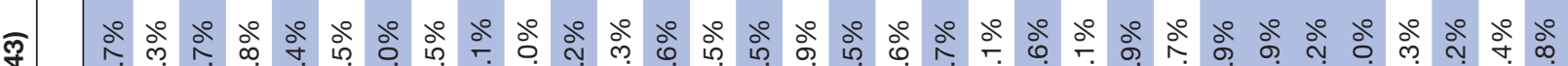

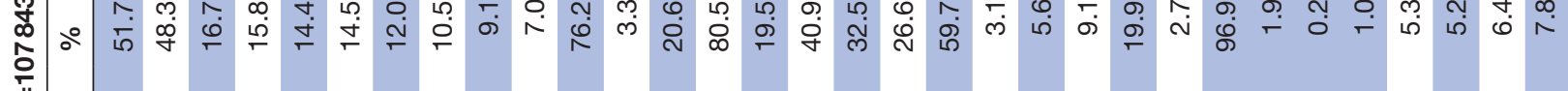

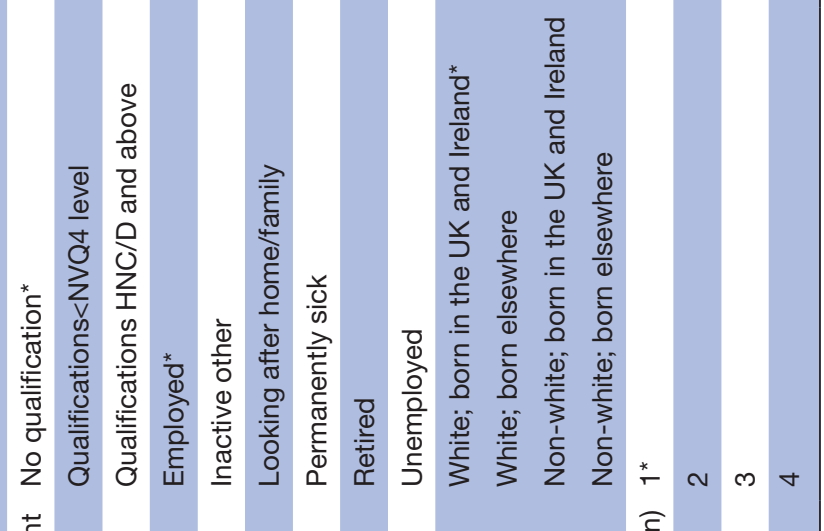

$\frac{1}{0}$
$\frac{0}{0}$
$\frac{0}{0}$
$\frac{0}{0}$
$\frac{0}{0}$
$\underline{\underline{c}}$
-
$\frac{0}{0}$
$\frac{0}{\sigma}$
10
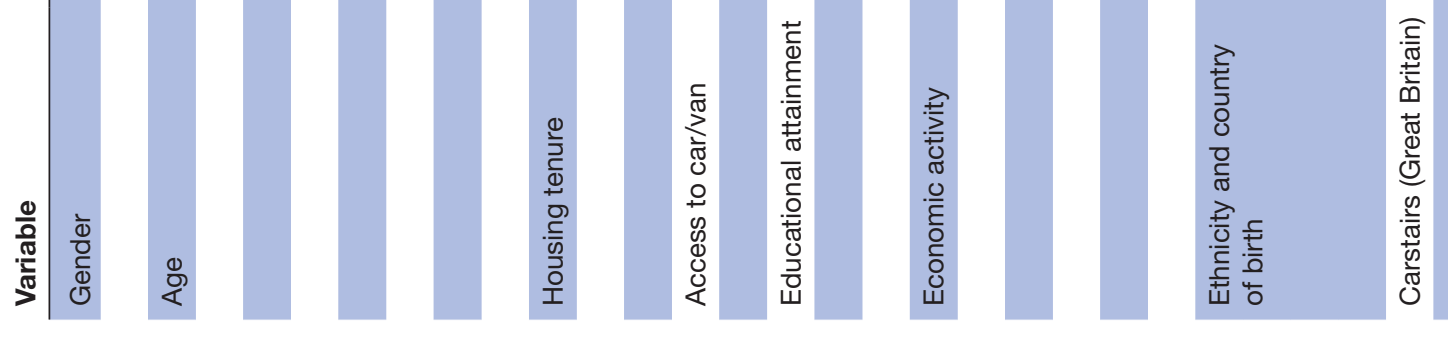

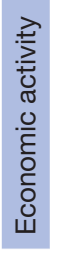
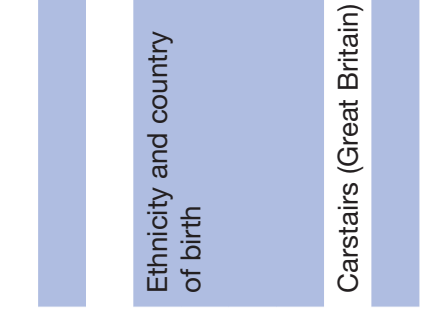


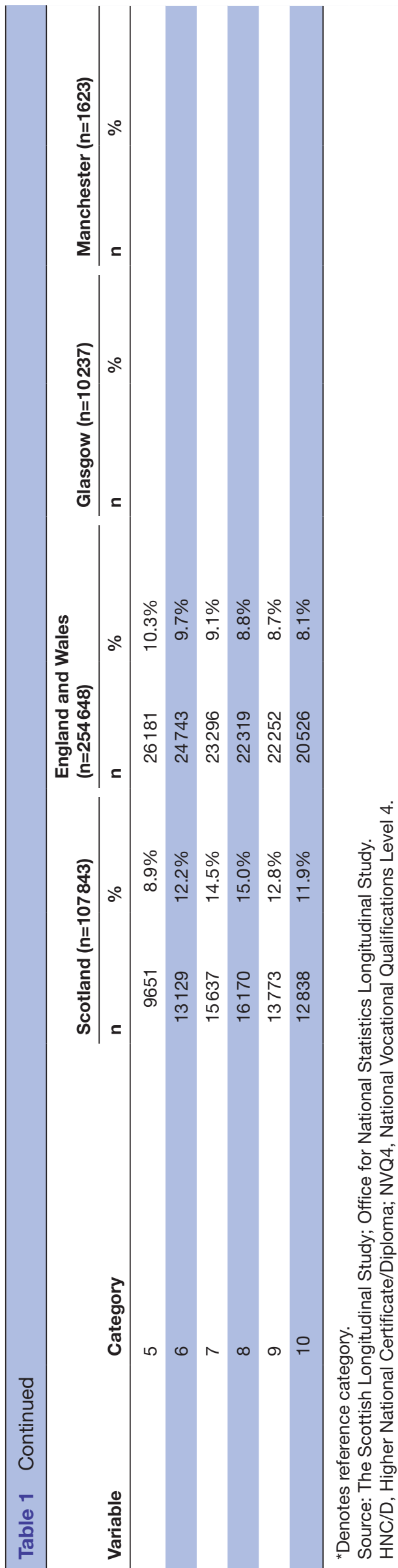

UK/Ireland; the equivalent overall figure for the Scottish sample was only $1.2 \%$, the vast majority of whom $(85 \%)$ had been born outside UK/Ireland. In Manchester, over $18 \%$ were non-White compared with only around $3 \%$ in Glasgow: in both cases, over $80 \%$ of the non-White population had been born outside UK/Ireland.

Table 2 summarises the results of the comparison of mortality analyses. Among 35-74years old, mortality in Glasgow was 33\% higher than in Manchester (incidence rate ratio (IRR) $1.33,95 \%$ CI 1.13 to 1.56 ). After adjustment for different measures of SEP, this was reduced to 25\% (IRR 1.25, 1.07 to 1.47). Further adjustment for the combined effect of ethnicity and country of birth reduced it further to $20 \%$ (IRR $1.20,1.02$ to 1.42 ). The equivalent figures for Scotland compared with England and Wales were: $18 \%$ higher mortality overall (IRR 1.18, 1.16 to 1.21 ), reduced to $10 \%$ after adjustment for SEP (IRR $1.10,1.07$ to 1.12 ), and further reduced to $7 \%$ after further adjustment for the combined effect of ethnicity and country of birth (IRR 1.07, 1.05 to 1.10).

Online appendix table D and E present similar figures for models for all ages and those aged 0-64 years. For example, mortality among $0-64$ year olds was shown to be $44 \%$ (IRR 1.44, 1.16 to 1.79) higher in Glasgow than in Manchester, reducing to 39\% (IRR 1.39, 1.11 to 1.72) after adjustment for SEP, and then reduced further to $31 \%$ (IRR 1.31, 1.05 to 1.64) after further adjustment for the combined effect of ethnicity and country of birth.

Table 3 (Scotland and England and Wales) and table 4 (Glasgow and Manchester) present the results of the full, final models for those aged 35-74 years. Expected greater risks of mortality were observed for, for example, men compared with women, older cohort members compared with younger, those with no access to a car/van compared with those with access, and those with no educational qualifications compared with higher level qualifications. In addition, however, differences were observed between the Scottish and English samples in terms of mortality among non-Whites born in UK/Ireland compared with non-Whites born outside UK/Ireland. Across all the samples, non-Whites born outside UK/Ireland had-after adjustment for all covariates-a lower risk of mortality than Whites born in UK/Ireland: approximately $35 \%$ lower risk in Scotland (IRR 0.65, 0.49 to 0.87 ), $31 \%$ lower in England and Wales (IRR 0.69, 0.65 to 0.74), $43 \%$ lower in Glasgow (IRR 0.57, 0.34 to 0.96 ) and $37 \%$ lower in Manchester (IRR 0.63, 0.36 to 1.11) (although in the latter case the smaller sample size resulted in much wider, and overlapping, confidence intervals). However, among the Scottish samples only, non-Whites born in UK/Ireland had a significantly higher risk of mortality compared with Whites born in UK/Ireland: 77\% higher risk for Scotland (IRR 1.77, 1.10 to 2.85) and more than three times higher for Glasgow (IRR 3.10, 1.28 to 7.51). It should be noted that the sample sizes for non-Whites born in the UK/ Ireland (and living in Scotland) in this age group are very small: thus, the results should be interpreted with caution. That said, however, similar results were obtained from 
Table 2 Overview of results of the Poisson regression modelling comparing all-cause mortality rates (1) for Scotland compared with England and Wales and (2) Glasgow compared with Manchester, 35-74 years

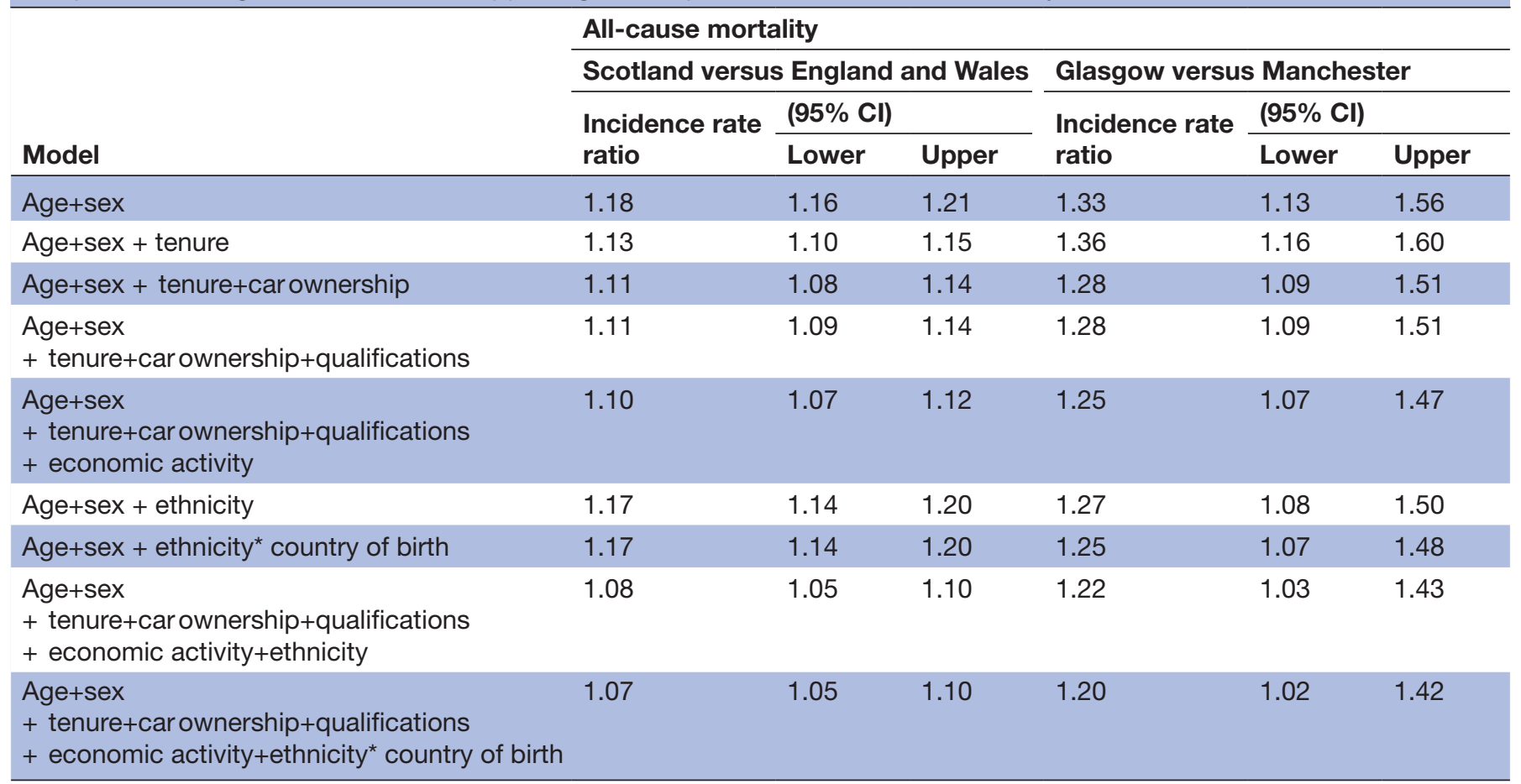

Source: The Scottish Longitudinal Study; Office for National Statistics Longitudinal Study.

the modelling based on bigger age groups, and therefore larger sample sizes (online appendix tables F-I).

\section{DISCUSSION}

\section{Overall findings and implications}

The analyses support the hypothesis that less ethnic diversity plays a small role in explaining high levels of Scottish excess mortality. Among 35-74years old, the excess (after adjustment for different measures of SEP) was reduced from 25\% to 20\% in Glasgow compared with Manchester, and from $10 \%$ to $7 \%$ in Scotland compared with England and Wales, after further adjustment for ethnicity. However, the change in the size of the ethnicity effect was small compared with the precision of the estimates, particularly for the comparison of Glasgow and Manchester. The lower mortality associated with the non-White population after adjusting for SEP related primarily to those born outside the UK. Among the Scottish samples only, mortality of non-Whites born in the UK was significantly higher than that of Whites born in the UK.

The latter finding warrants further research into the likely causes. More generally, despite the apparent contribution of ethnic diversity to relatively higher mortality in Scotland, it is notable that in Glasgow's case in particular a large excess remains. Thus, previously articulated policy implications aimed at addressing poverty, vulnerability and inequality clearly still apply. ${ }^{78}$

\section{Strengths and weaknesses}

There are a number of limitations associated with the analyses: the use of a binary White/non-White variable is less than ideal; as discussed in more detail next, the choice of SEP measure has been shown to be important in analyses of ethnicity and health, and in these analyses the choice was limited to what was collected in (or could be derived from) the census, and not all measures could be used in all models; the period of follow-up was limited to 10 years; the outcome was restricted to all cause, rather than cause-specific mortality; and the sample size for Manchester for the main age group (35-74 years) was relatively small $(n=1623)$ (indeed sample sizes at the city level were particularly challenging when broken down by ethnicity categories). However, it was not possible to include a more detailed breakdown of ethnicity categories because of sample size issues, and the use of the binary ethnicity variable in an interaction with country of birth still allowed us address both aims of the study. Although the choice of SEP indicators is indeed important, we were still able to use measures which have been shown previously to be important in explaining mortality differentials, ${ }^{7}$ and for some models we were able to include an additional measure of area deprivation. Levels of excess Scottish mortality within the 10-year follow-up period have been shown to be comparable with levels shown in other studies. ${ }^{6}$ Finally, the large sample size overall-more than 350000 people-is a key strength of the study, and the limitations of the smaller size for 35-74years old residents 
Table 3 Full Poisson regression model comparing all-cause mortality rates, Scotland versus England and Wales, 35-74 years

E-DataSHIELD:

Scotland, England and Wales

Scotland

England and Wales

Incidence rate ratio (IRR) (95\%

Cl)

IRR

Country

England and Wales* $\quad 1.00$

$\begin{array}{llll}\text { Scotland } & 1.07 & 1.05 & 1.10 \\ \text { Sex } & & & \end{array}$

\begin{tabular}{|c|c|c|c|c|c|c|c|c|c|}
\hline Females* & 1.00 & & & 1.00 & & & 1.00 & & \\
\hline Males & 1.56 & 1.53 & 1.60 & 1.53 & 1.47 & 1.60 & 1.58 & 1.54 & 1.62 \\
\hline \multicolumn{10}{|l|}{ Age group } \\
\hline $35-39^{*}$ & 1.00 & & & 1.00 & & & 1.00 & & \\
\hline $40-44$ & 1.57 & 1.43 & 1.72 & 1.38 & 1.18 & 1.62 & 1.67 & 1.49 & 1.87 \\
\hline $45-49$ & 2.60 & 2.38 & 2.84 & 2.41 & 2.08 & 2.79 & 2.70 & 2.42 & 3.00 \\
\hline $50-54$ & 3.73 & 3.44 & 4.05 & 3.37 & 2.93 & 3.87 & 3.91 & 3.53 & 4.33 \\
\hline $55-59$ & 5.43 & 5.01 & 5.88 & 4.95 & 4.32 & 5.68 & 5.67 & 5.13 & 6.26 \\
\hline $60-64$ & 8.28 & 7.65 & 8.97 & 7.34 & 6.41 & 8.41 & 8.75 & 7.93 & 9.65 \\
\hline $65-69$ & 13.74 & 12.66 & 14.91 & 12.12 & 10.54 & 13.95 & 14.53 & 13.14 & 16.07 \\
\hline $70-74$ & 22.15 & 20.42 & 24.04 & 19.13 & 16.62 & 22.02 & 23.66 & 21.40 & 26.16 \\
\hline
\end{tabular}

Tenure

\begin{tabular}{|c|c|c|c|c|c|c|c|c|c|}
\hline Owned $^{*}$ & 1.00 & & & 1.00 & & & 1.00 & & \\
\hline Private rent & 1.26 & 1.19 & 1.33 & 1.23 & 1.09 & 1.38 & 1.27 & 1.19 & 1.35 \\
\hline Social rent & 1.39 & 1.35 & 1.43 & 1.35 & 1.29 & 1.42 & 1.41 & 1.36 & 1.46 \\
\hline \multicolumn{10}{|l|}{ Car access } \\
\hline Car access* & 1.00 & & & 1.00 & & & 1.00 & & \\
\hline No car & 1.43 & 1.39 & 1.46 & 1.38 & 1.32 & 1.45 & 1.45 & 1.40 & 1.50 \\
\hline \multicolumn{10}{|l|}{ Educational attainment } \\
\hline No qualification* & 1.00 & & & 1.00 & & & 1.00 & & \\
\hline $\begin{array}{l}\text { Qualifications }<\text { NVQ4 } \\
\text { level }\end{array}$ & 0.89 & 0.87 & 0.92 & 0.90 & 0.85 & 0.95 & 0.89 & 0.86 & 0.92 \\
\hline $\begin{array}{l}\text { Qualifications HNC/D } \\
\text { and above }\end{array}$ & 0.78 & 0.75 & 0.81 & 0.78 & 0.73 & 0.83 & 0.77 & 0.74 & 0.81 \\
\hline \multicolumn{10}{|l|}{ Economic activity } \\
\hline Employed $^{*}$ & 1.00 & & & 1.00 & & & 1.00 & & \\
\hline Inactive other & 1.76 & 1.65 & 1.88 & 2.00 & 1.78 & 2.23 & 1.67 & 1.54 & 1.80 \\
\hline $\begin{array}{l}\text { Looking after home/ } \\
\text { family }\end{array}$ & 1.30 & 1.21 & 1.39 & 1.40 & 1.23 & 1.59 & 1.26 & 1.16 & 1.37 \\
\hline Permanently sick & 2.98 & 2.87 & 3.10 & 3.32 & 3.11 & 3.55 & 2.85 & 2.72 & 2.98 \\
\hline Retired & 1.40 & 1.35 & 1.46 & 1.59 & 1.48 & 1.71 & 1.33 & 1.27 & 1.39 \\
\hline Unemployed & 1.60 & 1.47 & 1.74 & 1.80 & 1.57 & 2.07 & 1.51 & 1.36 & 1.68 \\
\hline \multicolumn{10}{|l|}{$\begin{array}{l}\text { Ethnicity and country } \\
\text { of birth }\end{array}$} \\
\hline $\begin{array}{l}\text { White; born in the UK } \\
\text { and Ireland* }\end{array}$ & 1.00 & & & 1.00 & & & 1.00 & & \\
\hline $\begin{array}{l}\text { Non-white; born in the } \\
\text { UK and Ireland }\end{array}$ & 1.14 & 0.95 & 1.35 & 1.77 & 1.10 & 2.85 & 1.08 & 0.90 & 1.30 \\
\hline White; born elsewhere & 0.84 & 0.78 & 0.90 & 0.82 & 0.69 & 0.98 & 0.84 & 0.78 & 0.91 \\
\hline
\end{tabular}

IRR (95\% Cl)

Lower Upper IRR Lower Upper
R $(95 \% \mathrm{CI})$ 


\begin{tabular}{|c|c|c|c|c|c|c|c|c|c|}
\hline & \multicolumn{6}{|c|}{ E-DataSHIELD: } & \multicolumn{3}{|c|}{ England and Wales } \\
\hline & \multicolumn{3}{|c|}{$\begin{array}{l}\text { Incidence rate ratio (IRR) }(95 \% \\
\mathrm{Cl})\end{array}$} & \multicolumn{3}{|c|}{ IRR (95\% Cl) } & \multicolumn{3}{|c|}{ IRR (95\% Cl) } \\
\hline & IRR & Lower & Upper & IRR & Lower & Upper & IRR & Lower & Upper \\
\hline $\begin{array}{l}\text { Non-white; born } \\
\text { elsewhere }\end{array}$ & 0.69 & 0.65 & 0.74 & 0.65 & 0.49 & 0.87 & 0.69 & 0.65 & 0.74 \\
\hline
\end{tabular}

${ }^{*}$ Denotes reference category.

Source: The Scottish Longitudinal Study; Office for National Statistics Longitudinal Study.

of Manchester were offset by rerunning the models for larger age groups (0-64years old, and all ages), the results of which were broadly similar. Additional strengths of this research include the fact that the data are taken from national censuses and are thus not subject to sampling biases associated with population surveys, while the longitudinal nature of the data enabled a manner of testing hypotheses not possible with cross-sectional data. Finally, to our knowledge, this is the first time the important relationships among ethnicity, country of birth and mortality have been explored between different countries of the UK within the same study: this was made possible by the E-DataSHIELD methodology employed. ${ }^{621}$

\section{Relevance to other studies}

The results of the study add to the large evidence base relating to excess mortality in Scotland and Glasgow compared with elsewhere in the UK. ${ }^{1-8}$ In Glasgow's case, the size of the excess (prior to the additional adjustment for ethnicity) is similar to that shown in previous studies comparing mortality and deprivation in the city with both Manchester and Liverpool. For example, the 25\% excess shown here for age 35-74 years is almost identical to that shown by Ralston et al in previous analyses of the same data sets, ${ }^{6}$ while the $15 \%$ excess for all ages is very similar to that shown in a 2010 study based on cross-sectional data. ${ }^{4}$ For Scotland compared with England and Wales, the $10 \%$ excess is lower than that shown by Ralston et al $(13 \%)$. This is most likely explained by differences in the definition of the cohort: the previous study was based on comparison of those born and resident in Scotland with those born and resident in England and Wales (to match the methodology employed by previous research ${ }^{22}$ ), whereas the analyses reported here include persons from all countries of birth.

The research reported here appears to confirm the previously proposed protective effects of greater ethnic diversity on mortality rates, once socioeconomic factors have been taken into account. For example, using UK parliamentary constituencies, Tunstall et al examined the links between area deprivation, mortality and variation in sociodemographic factors including the size of the non-White minority population. ${ }^{9}$ They found that greater ethnic diversity was associated with lower death rates in comparing similarly highly deprived areas. A number of other studies have demonstrated worse health among non-White groups compared with the White population in England-but showed it to be largely explained by lower SEP. For example, Mindell et al showed that the poorer self-reported health among most minority non-White groups was entirely explained by differences in SEP $^{23}$ (although some other English studies were less conclusive regarding the impact of social position ${ }^{24}{ }^{25}$ ). The analyses reported here adjust for multiple measures of SEP and show lower all-cause mortality among non-Whites-but only for those born outside the UK/Ireland. This echoes recent findings by Wallace for England and Wales ${ }^{17}$ and by Bhopal et al for Scotland. ${ }^{18}$ Wallace's study showed that immigrants to England and Wales had lower mortality than the England and Wales-born White population, but that the descendants of immigrants (born in the UK) had higher mortality. However, that higher mortality was fully attenuated after adjustment for SEP. Bhopal et als study showed that among all non-White ethnic groups analysed (any mixed background, Indian, Pakistani, Bangladeshi, other S. Asian, Caribbean, African, Black Scottish or Other Black, Chinese), mortality among those born outside the UK/Ireland was lower than among those born in the UK/Ireland. Confirming the results of our own analyses, the majority of those groups (born outside UK/ Ireland) also had lower mortality than UK-born White Scots, while the majority of non-White groups born in the UK/Ireland had higher mortality than UK-born White Scots, although that (1) sample sizes meant that in many cases CIs were overlapping and (2) those particular analyses did not adjust for SEP. However, Chinese and Pakistani men were an exception: compared with UK-born White Scots, all-cause mortality was significantly lower in those groups both among those born in and outside the UK/Ireland.

As stated, the reasons for differences in health status between different ethnic groups have been shown to be highly complex. In particular, the relationships among health, ethnicity and different facets of SEP have been shown to be difficult to disentangle ${ }^{12}{ }^{26}$ : one review concluded that in seeking to understand this, the only solution is 'to live with complexity'. ${ }^{11}$ This relates to the complex, multidimensional nature of SEP, meaning that the choice of measure is important, and is dependent on 


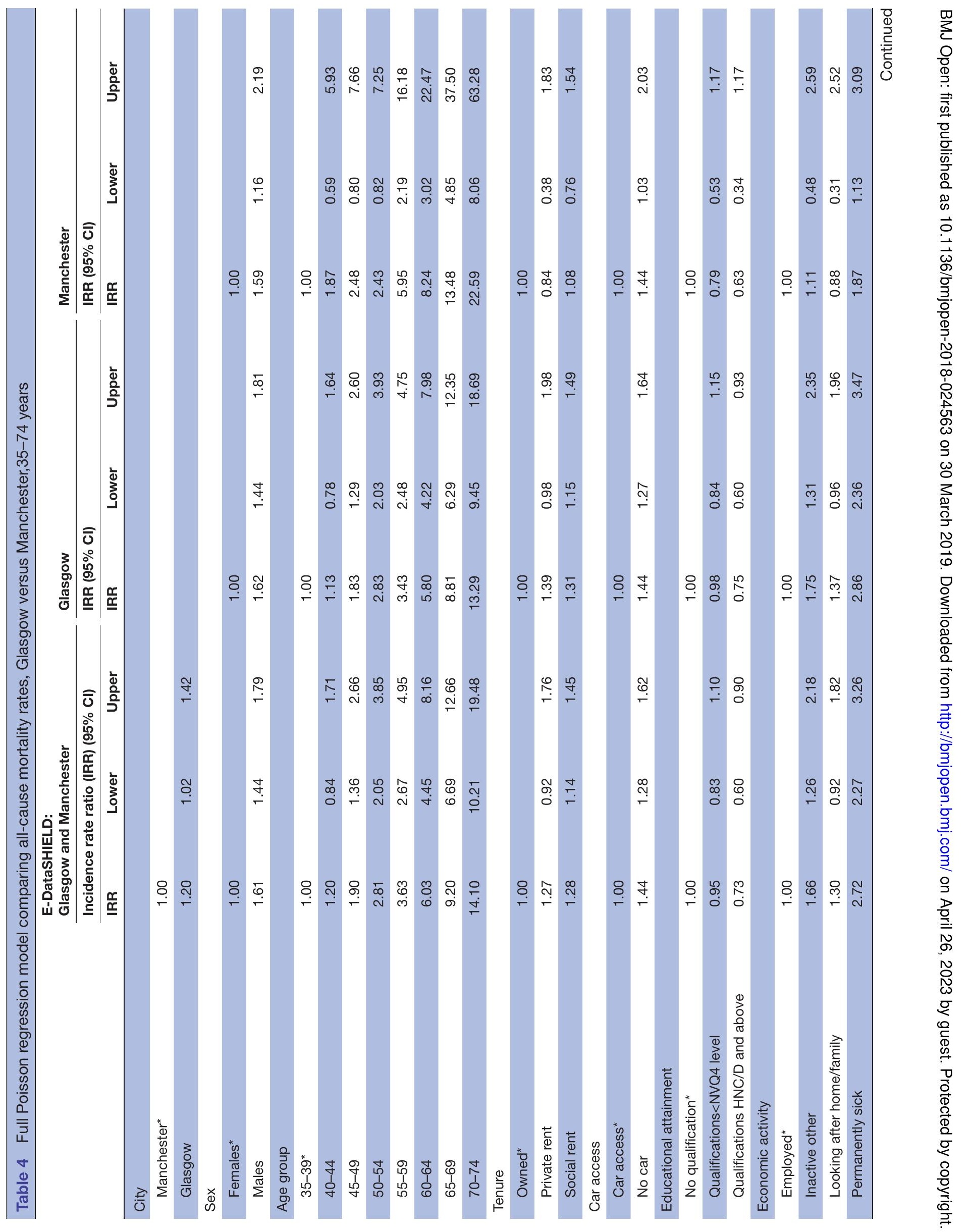




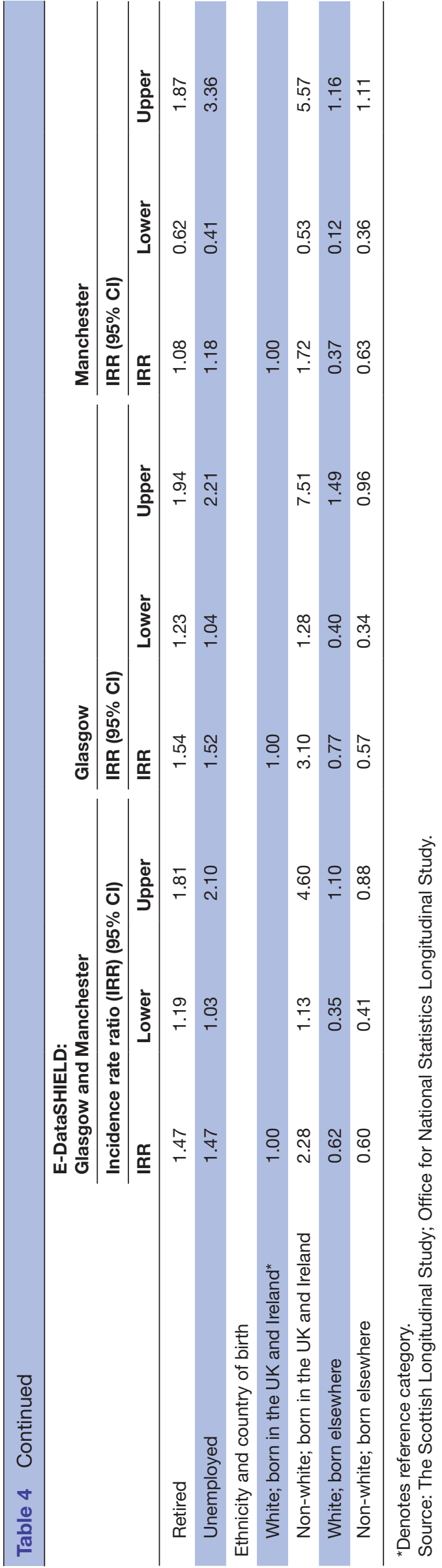

the population being studied and the research questions of interest. Social class artefact (inaccurate measurement and limitations of social class categories particularly affecting some ethnic groups) and the related issue of downward social mobility among migrants have been suggested as further complicating interpretation in this area. ${ }^{11}$ A recent large programme of research into ethnicity and health in Scotland ${ }^{27}$ further emphasised the importance of the choice of measure of SEP in a Scottish context. ${ }^{28}$ The same research provided evidence of varying levels of risk of particular diseases across different non-White ethnic groups: the impact of adjusting for SEP in the analyses was often minimal, but varied depending on the disease category studied. ${ }^{1429}$

Many other potential reasons for differences in health status between ethnic groups in the UK have been discussed. ${ }^{11131730}$ Of particular relevance to the lower mortality among non-Whites born outside UK/ Ireland shown here is the evidence of 'healthy migrant effects'. ${ }^{10} 11 \quad 1516$ Other protective effects have been proposed relating to health behaviours, linked in some cases to broader cultural influences. ${ }^{11}$ Other such cultural factors include religious participation and family support networks: in both cases, protective effects for health have been demonstrated. ${ }^{31}{ }^{32}$ In terms of understanding higher mortality in Scotland among non-Whites born in the UK, 'acculturation' (ie, changes over time in health-related behaviours and associated outcomes to be more like the existing population) may be relevant. ${ }^{33-36}$ The effects of racial discrimination are also important. Its impacts on health and mental well-being among minority groups is well known, and have been shown to be independent of $\mathrm{SEP}^{3738}$; it has been described as a 'fundamental cause' of poor health and, therefore, health inequalities. ${ }^{25} 39$ Language-related barriers to healthcare within the UK have been discussed. ${ }^{17}$ However, there is little evidence to support a major role for genetic differences: as Smith et al pointed out, there are larger genetic differences within ethnic groups than there are between them. ${ }^{10}$ Evidence for the so-called 'salmon bias', or 'remigration bias'- that is, lower mortality rates influenced by older, potentially sicker, migrants returning to their country of birth before death-is also limited, especially among European populations. ${ }^{10} 40$

Further research into issues raised by this study is warranted. In particular, it is important to understand reasons for the higher mortality of UK-born non-Whites resident in Scotland. Apart from the potential explanations already discussed (acculturation, racism, etc.), differences in the experiences and impacts of non-Whites living in greater or lesser ethnically diverse societies may be relevant, as might be differences between the countries in important interactions between ethnicity and indicators of SEP. This is also relevant to the different SEP profile of many non-White groups in Scotland compared with those in England: how precisely this plays out in the reduced mortality risk when adjusting for ethnicity needs clarification. Finally, among those non-Whites born 
outside the UK, obtaining information relating to length of duration in Scotland/UK might be helpful in understanding differences in mortality risk at different ages and between different ethnic groups. Unfortunately, length of duration is not collected in the UK censuses; thus, other approaches/data sources would be required.

\section{CONCLUSIONS}

The research supports the hypothesis that greater ethnic diversity (linked to migrants born outside the UK) in comparator populations plays a role in explaining Scottish excess mortality. In Glasgow's case in particular, however, a large excess remains: thus, previously articulated policy implications (addressing poverty, vulnerability and inequality) still apply. Further research is warranted into the relatively high mortality of non-Whites born within the UK/Ireland and resident in Scotland.

Acknowledgements The help provided by staff of the Longitudinal Studies Centre-Scotland (LSCS) is acknowledged. The LSCS is supported by the ESRC/ JISC, the Scottish Funding Council, the Chief Scientist's Office and the Scottish Government. The authors are responsible for the interpretation of the data. Census output is Crown copyright and is reproduced with the permission of the Controller of HMSO and the Queen's Printer for Scotland. The permission of the Office for National Statistics to use the Longitudinal Study is gratefully acknowledged, as is the help provided by staff of the Centre for Longitudinal Study Information \& User Support (CeLSIUS). CeLSIUS is supported by the ESRC Census of Population Programme under project ES/K000365/1. The authors alone are responsible for the interpretation of the data. This work contains statistical data from ONS which is Crown Copyright. The use of the ONS statistical data in this work does not imply the endorsement of the ONS in relation to the interpretation or analysis of the statistical data. This work uses research datasets which may not exactly reproduce National Statistics aggregates.

Contributors DW originally conceived the study. The research questions and analysis plan were agreed by all authors. LS undertook the analyses with support from ZF, DB and DW. DW drafted the manuscript. All authors provided substantial critical input to improve the manuscript, and all authors approved the final draft.

Funding The analysis was funded by the Glasgow Centre for Population Health. Competing interests None declared.

Patient consent for publication Not required.

Provenance and peer review Not commissioned; externally peer reviewed.

Data sharing statement № additional data available.

Open access This is an open access article distributed in accordance with the Creative Commons Attribution Non Commercial (CC BY-NC 4.0) license, which permits others to distribute, remix, adapt, build upon this work non-commercially, and license their derivative works on different terms, provided the original work is properly cited, appropriate credit is given, any changes made indicated, and the use is non-commercial. See: http://creativecommons.org/licenses/by-nc/4.0/.

\section{REFERENCES}

1. Hanlon P, Lawder RS, Buchanan D, et al. Why is mortality higher in Scotland than in England and Wales? Decreasing influence of socioeconomic deprivation between 1981 and 2001 supports the existence of a 'Scottish Effect'. J Public Health 2005;27:199-204.

2. McCartney G, Russ TC, Walsh D, et al. Explaining the excess mortality in Scotland compared with England: pooling of 18 cohort studies. J Epidemiol Community Health 2015;69:20-7.

3. Schofield L, Walsh D, Munoz-Arroyo R, et al. Dying younger in Scotland: trends in mortality and deprivation relative to England and Wales, 1981-2011. Health Place 2016;40:106-15.

4. Walsh D, Bendel N, Jones R, et al. It's not 'just deprivation': why do equally deprived UK cities experience different health outcomes? Public Health 2010;124:487-95.
5. Graham P, Walsh D, McCartney G. Shipyards and sectarianism: how do mortality and deprivation compare in Glasgow and Belfast? Public Health 2012;126:378-85.

6. Ralston K, Walsh D, Feng Z, et al. Do differences in religious affiliation explain high levels of excess mortality in the UK? J Epidemiol Community Health 2017;71:493-8.

7. Walsh D, McCartney G, Collins C, et al; politics and vulnerability: explaining excess mortality in Scotland and Glasgow. Glasgow: Glasgow Centre for Population Health, 2016.

8. Walsh D, McCartney G, Collins C, et al. History, politics and vulnerability: explaining excess mortality in Scotland and Glasgow. Public Health 2017;151:1-12.

9. Tunstall H, Mitchell R, Gibbs J, et al. Socio-demographic diversity and unexplained variation in death rates among the most deprived parliamentary constituencies in Britain. J Public Health 2012;34:296-304.

10. Smith GD, Chaturvedi N, Harding S, et al. Ethnic inequalities in health: A review of UK epidemiological evidence. Crit Public Health 2000;10:375-408.

11. Smith GD. Learning to live with complexity: ethnicity, socioeconomic position, and health in Britain and the United States. Am J Public Health 2000;90:1694-8.

12. Stronks K, Kunst AE. The complex interrelationship between ethnic and socio-economic inequalities in health. J Public Health 2009;31:324-5.

13. Krieger N. Epidemiology and the People's Health. Theory and context. Oxford: Oxford University Press, 2011.

14. Walsh D, Buchanan D, Douglas A, et al. Increasingly diverse: the changing ethnic profiles of Scotland and Glasgow and the implications for population health. Appl Spat Anal Policy 2018;68.

15. Razum O. Migrant mortality, healthy migrant effect. In: Kirch W, ed. Encyclopedia of public health. 2. New York: Springer, 2008.

16. Singh GK, Siahpush M. All-cause and cause-specific mortality of immigrants and native born in the United States. Am J Public Health 2001;91:392-9.

17. Wallace M. Adult mortality among the descendants of immigrants in England and Wales: does a migrant mortality advantage persist beyond the first generation? J Ethn Migr Stud 2016;42:1558-77.

18. Bhopal RS, Gruer L, Cezard G, et al. Mortality, ethnicity, and country of birth on a national scale, 2001-2013: a retrospective cohort (Scottish Health and Ethnicity Linkage Study). PLoS Med 2018;15:e1002515

19. Boyle PJ, Feijten P, Feng Z, et al. Cohort Profile: the Scottish Longitudinal Study (SLS). Int J Epidemiol 2009;38:385-92.

20. Goldring S, Newman J. The ONS Longitudinal Study - a prestigious past and a bright future. Popul Trends 2010;139:4-10.

21. Wolfson M, Wallace SE, Masca N, et al. DataSHIELD: resolving a conflict in contemporary bioscience--performing a pooled analysis of individual-level data without sharing the data. Int $J$ Epidemiol 2010;39:1372-82.

22. Popham F, Boyle PJ. Is there a 'Scottish effect' for mortality? Prospective observational study of census linkage studies. J Public Health 2011;33:453-8.

23. Mindell JS, Knott CS, Ng Fat LS, et al. Explanatory factors for health inequalities across different ethnic and gender groups: data from a national survey in England. J Epidemiol Community Health 2014;68:1133-44.

24. Harding S, Maxwell R. Differences in mortality of migrants. In: Drever F, Whitehead M, eds. Health Inequalities. London: The Stationary Office, 1997

25. Nazroo JY. The health of Britain's ethnic minorities: findings from a national survey. London: PSI, 1997.

26. Kelaher M, Paul S, Lambert H, et al. The impact of different measures of socioeconomic position on the relationship between ethnicity and health. Ann Epidemiol 2008;18:351-6.

27. Bhopal R, Fischbacher C, Povey C, et al. Cohort profile: Scottish health and ethnicity linkage study of 4.65 million people exploring ethnic variations in disease in Scotland. Int J Epidemiol 2011;40:1168-75.

28. Fischbacher CM, Cezard G, Bhopal RS, et al. Measures of socioeconomic position are not consistently associated with ethnic differences in cardiovascular disease in Scotland: methods from the Scottish Health and Ethnicity Linkage Study (SHELS). Int J Epidemiol 2014;43:129-39.

29. Scottish Health and Ethnicity Linkage Study (SHELS). http://www.ed ac.uk/usher/scottish-health-ethnicity-linkage (Accessed Jul 2017).

30. Gordon DS, Graham L, Robinson M, et al. Dimensions of diversity: population differences and health improvement opportunities. Glasgow: NHS Health Scotland, 2010.

31. Koenig H, McCullough M, Larson D. Handbook of Religion and Health. New York: Oxford University Press, 2001. 
32. Kawachi I. Social capital and community effects on population and individual health. Ann N Y Acad Sci 1999;896:120-30.

33. Hawkins SS, Lamb K, Cole TJ, et al. Influence of moving to the UK on maternal health behaviours: prospective cohort study. BMJ 2008;336:1052-5.

34. Ajetunmobi O, Whyte B, Chalmers $\mathrm{J}$, et al. Informing the 'early years' agenda in Scotland: understanding infant feeding patterns using linked datasets. $J$ Epidemiol Community Health 2014;68:83-92.

35. Delavari M, Sønderlund AL, Swinburn B, et al. Acculturation and obesity among migrant populations in high income countries--a systematic review. BMC Public Health 2013;13:458.

36. Thomson MD, Hoffman-Goetz L. Defining and measuring acculturation: a systematic review of public health studies with Hispanic populations in the United States. Soc Sci Med 2009:69:983-91.

37. Nazroo JY. The structuring of ethnic inequalities in health: economic position, racial discrimination, and racism. Am J Public Health 2003;93:277-84.

38. Karlsen S, Nazroo JY. Relation between racial discrimination, social class, and health among ethnic minority groups. Am J Public Health 2002;92:624-31.

39. Hatzenbuehler ML, Phelan JC, Link BG. Stigma as a fundamental cause of population health inequalities. Am J Public Health 2013;103:813-21.

40. Norredam M, Hansen $\mathrm{OH}$, Petersen $\mathrm{JH}$, et al. Remigration of migrants with severe disease: myth or reality?--a register-based cohort study. Eur J Public Health 2015;25:84-9. 